\title{
La Vía de los 7 Saberes: promoviendo valores en la juventud para el desarrollo sostenible. 20 años después, la novedad sigue viva*
}

\section{Resumen}

\author{
Luis Carrizo*
}

El texto presenta la obra de Edgar Morin "Los siete saberes necesarios para la educación del futuro", desde su origen, destacando su relevancia y actualidad, veinte años después de su publicación. Destaca los eventos y documentos resultantes de su reflexión y también describe y explica en detalle el proyecto "La vía de los siete saberes. Promoviendo valores en la juventud para el desarrollo sostenible", en desarrollo y promovido por la Oficina Regional de Ciencia de la UNESCO para América Latina y el Caribe. El proyecto quiere contribuir a los objetivos fijados en la Agenda 2030 para el Desarrollo Sostenible, suscripta por las Naciones Unidas en septiembre de 2015. Palabras clave: Siete saberes, Edgar Morin, Investigación, Desarrollo sostenible, Juventud.

* Parte de este artículo se basa en la nota publicada por el autor en el número inaugural de "la diaria educación", periódico uruguayo especializado en educación, con fecha 3 de mayo de 2017.

** Es Psicólogo, especializado en Psicología Social. Magister en Desarrollo Regional y Local. Con estudios de Doctorado en Ciencia Política de la Universidad Sorbonne-Nouvelle Paris 3. Consultor de la Oficina Regional de Ciencias de UNESCO para América Latina y el Caribe, donde es Coordinador Académico del Proyecto "La vía de los 7 saberes". Ha sido Vicerrector Académico del Centro Latinoamericano de Economía Humana (Universidad CLAEH) y actualmente es Coordinador de su Cátedra Regional de Complejidad y Condición Humana. Consultor y asesor de diversos organismos internacionales (UNESCO, UNFPA, OEA, BID, OEI, SEGIB), y Profesor invitado de más de 30 Universidades de América Latina, Europa y África. Miembro de la Red Internacional de Pensamiento Complejo. E-Mail: luis.carrizo54@gmail.com e sitio: https://luiscarrizo.academia.edu/ 


\section{A Via dos Sete Saberes: promovendo valores à juventude para o desenvolvimento sustentável. 20 anos depois, a novidade permanece viva}

\section{Resumo}

O texto apresenta a obra "Os sete saberes necessários à educação do futuro", de Edgar Morin, desde a sua origem, com destaque para a sua pertinência e atualidade, vinte anos depois de sua publicação. Destaca eventos e documentos oriundos de sua reflexão e ainda descreve e explica detalhadamente o projeto "A via dos sete saberes: promovendo valores à juventude para o desenvolvimento sustentável”, em desenvolvimento e promovido pela Oficina Regional de Ciencias da UNESCO para a América Latina e o Caribe. O projeto quer contribuir com os objetivos estabelecidos na Agenda 2030 para o Desenvolvimento Sustentável, com o apoio das Nações Unidas, em Setembro de 2015.

Palavras-chave: Sete saberes, Edgar Morin, Pesquisa, Desenvolvimento sustentável, Juventude.

\section{The way of the Seven Knowledge: promoting values to youth for sustainable development. 20 years later, the new is still alive}

\section{Abstract}

The text presents Edgar Morin's work “The seven knowledge necessary for the education of the future", since its origin, highlighting its relevance and currentness, twenty years after its publication. It highlights events and documents arising from its reflection and also describes and explains in detail the project "The way of the seven knowledges: promoting values for youth for sustainable development", under development and promoted by the UNESCO Regional Science Workshop for Latin America and the Caribbean. The project wants to contribute to the objectives set out in the 2030 Agenda for Sustainable Development, with the support of the United Nations, in September 2015.

Keywords: Seven knowledges, Edgar Morin, Research, Sustainable development, Youth.

\section{En los orígenes, la obra básica: "Los siete saberes..."}

Se trató de un proceso largo y desafiante, personal y colectivo, construido en presente y en futuro. Con la densidad de la res- 
ponsabilidad histórica y la determinación de una corriente de ideas que construye su propio cauce y busca su destino. En sus orígenes, se encontraba una rica historia de producción de uno de los pensadores más lúcidos del siglo, con sus varias regeneraciones intelectuales y emocionales: Edgar Morin, el "omnívoro intelectual", el resistente contra todas las barbaries y totalitarismos.

En sus orígenes, se encontraba una organización internacional con vocación de paz y con la misión de promover las mejores causas para la convivencia planetaria, desde las ciencias, la educación y la cultura. Se trata de la UNESCO que, en el Preámbulo de su Constitución declara que: "puesto que las guerras nacen en la mente de los hombres, es en la mente de los hombres donde deben erigirse los baluartes de la paz".

En sus orígenes, se encontraba alguien que comprendía perfectamente el valor estratégico de la educación para enfrentar los desafíos del Siglo XXI: Federico Mayor Zaragoza, entonces Director General de la UNESCO, hombre de ciencia y cultura para la paz. En sus orígenes, se encontraba un momento bisagra en la historia de la humanidad: el pasaje de siglo y de milenio no era sólo un cambio de año. Se trataba de un cambio de época, una nueva mundialización: era necesario navegar en mares turbulentos con horizontes inciertos.

En fin, todo ello se conjugó para que la UNESCO le solicitara a Edgar Morin una contribución a la reflexión internacional sobre cómo educar para un futuro sostenible. El resultado fue un texto que expone problemas capitales-siete saberes "fundamentales"- que la educación del futuro debe tratar en cualquier sociedad y cultura. Así nació esta obra formidable, que constituye una referencia para todos aquellos que se preocupen y ocupen en la construcción de un mundo mejor: "Los siete saberes necesarios para la educación del futuro".

La obra, de intensas 65 páginas en la edición inaugural publicada por UNESCO, se compone de siete capítulos/saberes -siete principios claves- a través de los cuales Morin construye una cosmovisión esencial para el campo educativo y para las transformaciones sociales y subjetivas. 
En ellos, nos habla de algunas claves para concebir y actuar en el mundo contemporáneo, describiendo los principios que debemos tener presente al diseñar o reformar los sistemas y las prácticas educativas:

- Las cegueras del conocimiento provocadas por el error y la ilusión, apelando a la necesidad de formular un conocimiento de segundo grado - el conocimiento del conocimiento-, como práctica permanente que oriente nuestra acción.

- Los principios de un conocimiento pertinente, capaz de abordar los problemas globales y fundamentales y que, a la vez, dialogue con los asuntos más próximos y locales. Esto exige la recuperación del conocimiento integrado, superando la fragmentación en parcelas inconexas y estériles.

- La condición humana como objeto esencial de aprendizaje, conjugando unidad y diversidad de lo humano en toda su complejidad.

- La identidad terrenal como destino planetario del género humano, apropiándose del ethosde la ciudadanía global, desde una identidad compleja, a la vez local y global.

- La incertidumbre como factor de nuevas estrategias de desarrollo y construcción de futuro, aprendiendo a "navegar en un océano de incertidumbres a través de archipiélagos de certeza".

- La comprensión, como medio y fin de la comunicación humana. En una época en donde la incomprensión parece ser tendencia dominante, resulta capital enseñar la comprensión y la educación para la paz.

- La ética del género humano, desde una concepción compleja de la condición humana, construida en el bucle individuo $\leftrightarrow$ sociedad $\leftrightarrow$ especie, con sus interdependencias en términos de autonomía individual, participación colectiva y responsabilidad estratégica.

Estas claves, presentadas por el autor en un lenguaje claro y breve, deben servir para revisar paradigmas, sistemas y prácticas en 
distintas áreas del quehacer humano. Entre ellas, la educación, por su fenomenal impacto en la construcción y destino de las sociedades, tiene aquí un recurso estratégico.

En el Prólogo escrito para esta obra, el entonces Director General de la UNESCO, Federico Mayor Zaragoza, realiza un llamamiento a "trabajar para construir un futuro viable". Allí señala que, para ello, "uno de los desafíos más difíciles será el de modificar nuestro pensamiento de manera que enfrente la complejidad creciente, la rapidez de los cambios y lo imprevisible que caracterizan nuestro mundo."

"Los siete saberes necesarios para la educación del futuro" no es sólo un libro de referencia mundial, y no lo es sólo para educadores. En realidad, se parece más a un movimiento, una gran fuente de inspiración y convergencia para múltiples colectivos. Se trata de una obra que ha sido traducida a más de 20 lenguas, y su edición en español se encuentra sistemáticamente desde hace años entre los cinco documentos más solicitados en la Biblioteca Digital de la UNESCO.

En América Latina, en especial, su incidencia en el pensamiento pedagógico y social ha sido de enorme trascendencia, con gran adhesión de comunidades de educadores de los países de la región. En especial, queremos hacer referencia aquí a dos eventos de gran importancia, que dieron lugar a sendos documentos basados en la obra moriniana que aquí reseñamos. Se trata de las Conferencias de Fortaleza (Ceará, Brasil) realizadas en 2010 y 2016: la Conferencia Internacional "Por una educación transformadora: los siete saberes para la educación del presente" (setiembre 2010) y la Conferencia Internacional "Saberes para una ciudadania planetaria" (mayo de 2016).

En la Carta de Fortaleza (2010), se expresa:

- La importancia de este precioso legado para la formación de las futuras generaciones, titulado 'Los siete saberes necesarios de la educación para el futuro", propuesto por Edgar Morin, que a petición de la UNESCO nos compromete a promover con urgencia, una agenda que viabilice su puesta en práctica junto 
a las instituciones educativas de nuestros países, ya sean públicas o privadas, formales y no formales.

- El interés y compromiso con "Los Siete Saberes" propuestos en el mencionado documento y la importancia de crear espacios dialógicos, creativos, reflexivos y democráticos, formales y no formales, capaces de facilitar la creación de prácticas pedagógicas basadas en estos temas y guiadas por la solidaridad, la ética, la pazy la justicia social.

Porsuparte, más aquíen eltiempo, laCartadeFortalezaII(2016) , entre otros asuntos estratégicas, recomienda y apoya la creación de una red de cooperación interinstitucional e internacional capaz de colocar en marcha estrategias intensivas de formación de educadores, mediante el desarrollo de proyectos compartidos de investigación-formación-innovación, pautados por la complejidad y la transdisciplinariedad, así como por los demás principios que inspiran los documentos "Para un Pensamiento del Sur" y "Los siete saberes para una educación del futuro", en vistas a la construcción de una nueva política de civilización planetaria.

Son incontables las instancias de elaboración pedagógica que, en nuestra región, han tenido como base y contenido el mensaje de "Los siete saberes...". Últimamente, también se están dedicando esfuerzos a la adaptación de sus contenidos en otros formatos, con vocación de vínculo directo con adolescentes y jóvenes. Este es el caso del proyecto "La vía de los siete saberes. Promoviendo valores en la juventud para el desarrollo sostenible" , que lleva adelante la Oficina Regional de Ciencias de la UNESCO para América Latina y el Caribe.

A través de esta iniciativa, se busca acercar a los jóvenes el mensaje de la obra moriniana, de manera innovadora, para contribuir a desarrollar una visión más integral sobre la complejidad del mundo y sus incertidumbres. Por medio de dispositivos tecnológicos - narrativas transmedia, múltiples plataformas - el proyecto contribuye a identificar los retos y alternativas que surgen en 
un mundo cada día más complejo, desafiante y prometedor. Los productos creados por el proyecto se conciben para ser utilizados como herramientas educativas en ámbitos formales y no-formales, ofreciendo un abordaje pertinente a la complejidad del mundo real, y contribuyendo a fortalecer vínculos sociales inclusivos, valores humanos de comprensión mutua y visiones responsables de futuro.

Tal como se expresa al inicio de esta nota, 20 años más tarde la novedad de "Los siete saberes..." aún sigue inspirando alternativas y estrategias de futuro. Como gusta recordar Edgar Morin de uno de sus poetas preferidos, Antonio Machado: "Caminante, no bay camino, se hace camino al andar'.

\section{Aplicación digital educativa "La Vía de los 7 Saberes"}

La creciente complejidad de las sociedades contemporáneas reclama formas más inteligentes e innovadoras de comprender el mundo y actuar en nuestra propia vida cotidiana. Para responder a estas exigencias de forma exitosa y con visión estratégica, todos los medios a nuestro alcance pueden ser útiles. Entre ellos, la imaginación: herramienta universal para enfrentar los grandes desafíos de la aventura de vivir.

Desde esta perspectiva, la utilización de recursos de tecnologías de la información y comunicación puede contribuir decisivamente a la promoción de una cultura de convivencia para el desarrollo sostenible. Esto es especialmente prometedor entre las jóvenes generaciones, en razón de su fuerte vínculo con la cultura tecnológica e informática, incluyendo redes, dispositivos y aplicaciones.

El Proyecto "La vía de los 7 saberes", realizado por la Oficina de Ciencias de UNESCO para América Latina y el Caribe - con el apoyo del Centro Internacional para el Desarrollo Sostenible (CIDES, Panamá) y el Plan Ceibal (Uruguay) -, busca contribuir a promover en los jóvenes estudiantes panameños una cultura de convivencia para el desarrollo sostenible, a través de la utilización de una aplicación digital educativa, inspirada en "Los siete 
saberes necesarios para la educación del futuro”. Bajo la Supervisión Científica de Edgar Morin, este proyecto constituye un nuevo abordaje al mensaje universal de la UNESCO, promoviendo transformaciones sociales hacia la comprensión mutua y la solidaridad.

A su vez, el proyecto quiere contribuir a los objetivos fijados en la Agenda 2030 para el Desarrollo Sostenible, suscripta por las Naciones Unidas en Setiembre de 2015 bajo la denominación "Transformando nuestro mundo". En este ambicioso documento, que establece la visión de los países firmantes sobre los desafíos del desarrollo, los Estados miembros de las Naciones Unidas culminan estableciendo que:

El futuro de la humanidad y de nuestro planeta está en nuestras manos. También está en las manos de las jóvenes generaciones de hoy, que pasarán la antorcha a las generaciones futuras. Hemos trazado el camino al desarrollo sostenible; el compromiso de todos nosotros será el que asegure que la travesía sea exitosa y sus resultados irreversibles.

En este marco institucional, el sentido del proyecto "La vía de los 7 saberes" tiene la vocación de contribuir a las causas defendidas por la UNESCO y las Naciones Unidas, desde una acción innovadora y concreta, ligada directamente a las transformaciones sociales y al protagonismo de las nuevas generaciones en la aventura por un futuro viable.

\section{Presentación}

Los contenidos y metodologías de esta Aplicación Digital Educativa han sido concebidos tomando especialmente en cuenta el contexto institucional y la comunidad del INADEH de Panamá. Para ello, se ha realizado un proceso de permanente articulación entre las distintas partes involucradas. Las escenas y diálogos que integran los contenidos de esta versión de la Aplicación Digital han sido concebidos tomando en cuenta la cultura y lenguaje locales. 
La Aplicación Digital tiene el cometido de ofrecer espacios de aprendizaje de los siete saberes propuestos por Edgar Morin, así como metodologías para su aplicación en distintos ámbitos, por parte de los estudiantes del INADEH. Es decir, el conocimiento aplicado es una noción clave de esta propuesta: por una parte, se abre un espacio de aprendizaje reflexivo y compartido sobre cada uno de los siete saberes que integran la obra original; por otra, se propone una serie de actividades (proyectos) donde se aplicarán esos saberes en la transformación y mejora de la realidad concreta.

\section{(6) OBJETIV SSODESARROLLO}
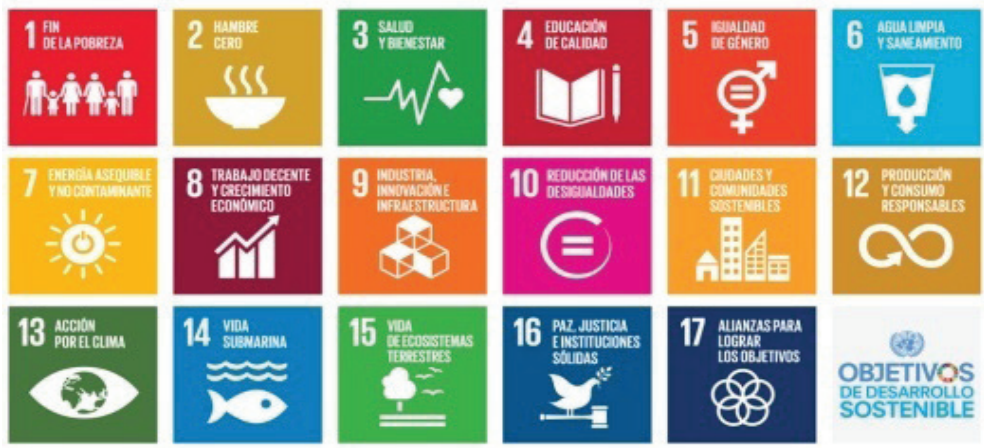

(अ)

OBJETIVOS DEDESARROLLO

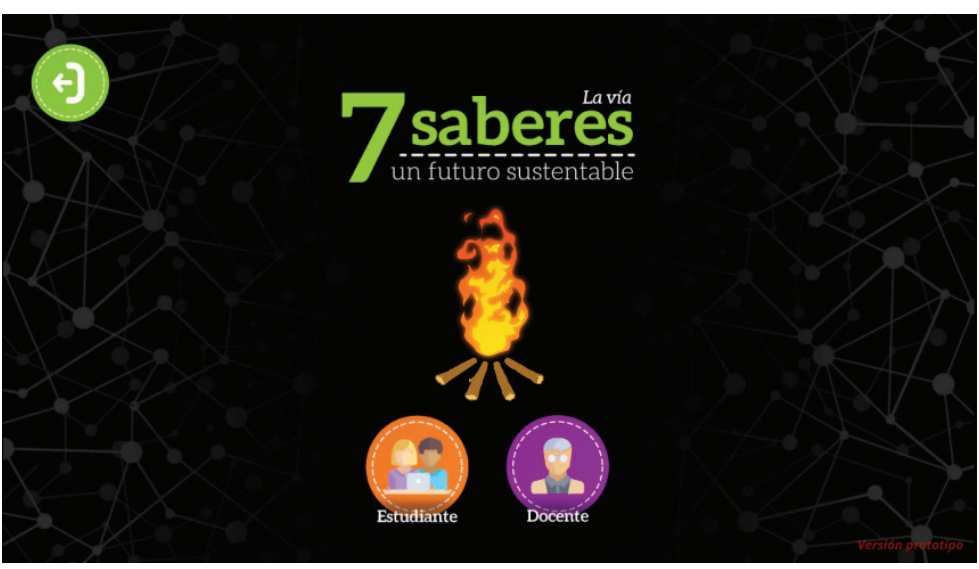


Esta Aplicación está destinada a ser utilizada en aula o fuera de ella, de manera individual o colectiva, guiada por el docente o autogenerada por el estudiante. Entre otras cualidades, su riqueza reside precisamente en la versatilidad de la utilización de sus contenidos. Asimismo, el docente podrá hacer uso de las sugerencias de actividades que están integradas a la Aplicación Digital, pero no necesariamente se debe restringir a ellas: por el contrario, se estimula la creatividad docente para imaginar actividades que puedan aprovechar de mejor manera estos contenidos en el ámbito educativo. Y también lo pueden hacer en consulta con sus colegas, y por supuesto, de manera interactiva con el grupo de estudiantes, ya que se trata de estimular la inteligencia colectiva.

\section{Navegando la Aplicación Digital}

En la pantalla de inicio, se aprecian dos niveles de actividad: la Unidad Central, denominada "La fogata de los 7 saberes", y la Unidad de Proyectos. Estas dos Unidades están estrechamente conectadas entre sí: una se alimenta de la otra. La Unidad Central es el lugar donde cada uno de los saberes se presenta, se explora, se comprende, se integra como conocimiento de vida.

La Unidad de Proyectos, por su parte, es el lugar donde estos saberes se ponen en juego para comprender y transformar para mejor nuestras realidades, ya sea en el plano grupal, como en el plano de nuestra comunidad o de nuestro planeta.

\section{Unidad Central}

En esta Unidad se aborda cada uno de los saberes a través de distintas actividades lúdico-didácticas. Uno de los mayores desafíos en el diseño de esta Unidad ha sido, precisamente, lo que es el corazón del proyecto: adaptar activamente el mensaje de los "7 saberes" a realidades concretas y próximas. Para ello, en la Aplicación hemos elaborado un "guión”, “escenas" y "personajes". Se ha instalado lo que se denomina "La fogata de los 7 saberes", como una puesta en escena que permite introducir las distintas temáticas de una manera informal, comprensible y próxima. 
Un grupo de amigos -Yamila, Joaco, Abril, Fede- conversan alrededor de una fogata en la playa, de manera distendida, y a la vez, con diálogos provocadores de reflexión. Cada conocimiento comienza por un breve diálogo de presentación, y cada diálogo se apoya en un elemento particular del saber al que corresponde. Por ejemplo: en el Saber 1 ("Las cegueras del conocimiento: el error y la ilusión") se ha optado por utilizar el "malentendido" como clave temática del diálogo, situación seguramente conocida por todos y que abre la puerta al debate sobre el Saber 1. En el Saber 2 ("Los principios de un conocimiento pertinente"), hemos elegido el par "texto/contexto" para comenzar el camino hacia este saber.

La elaboración de estos diálogos ha sido cuidadosamente considerada, en

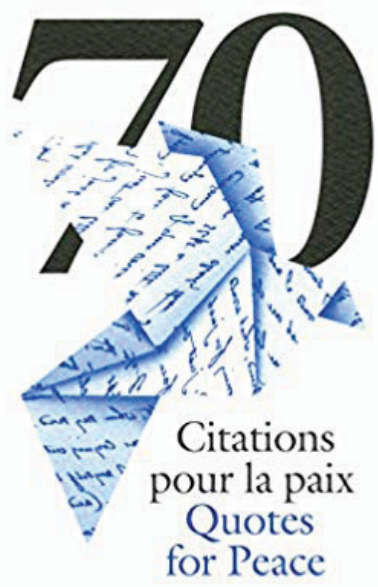

(iiin)। Gallimard términos de comprensión del mensaje, agilidad del intercambio, familiaridad de los temas abordados. De esta forma, el docente puede disponer de una introducción al saber que resulte atractiva para el estudiante y con suficiente potencial de trabajo para el progreso educativo. Por supuesto, es recomendable que el docente haya leído la obra original, que puede descargarse de manera gratuita en el sitio http://unesdoc.unesco. org/images/0011/001177/ 117740so.pdf

Desde esta introducción dialogada entre los personajes, cada saber se deriva a distintas actividades didácticas que tienen el cometido de afianzar y consolidar el conocimiento del saber y su enriquecimiento de sentido. En la Aplicación se ha incluido variadas 
actividades, tanto de reflexión (individual y colectiva), debate grupal, ejercicios y tareas a realizar, así como instancias lúdicas que tienen el cometido de verificar los progresos del aprendizaje (múltiple opción, correcto/incorrecto, juego de arrastre). Asimismo, durante todo el proceso (saber a saber y en su conjunto), la retroalimentación es importante a efectos de estimular y mantener el interés del estudiante en la actividad. De esta forma, se ofrecen recompensas (medallas, trofeos), que colaboran con la autoestima, pero también se ofrece un sentido de promoción de la mejora a través de la progresiva restauración del Planeta Tierra, que aparece como ícono del progreso del aprendizaje de los saberes.

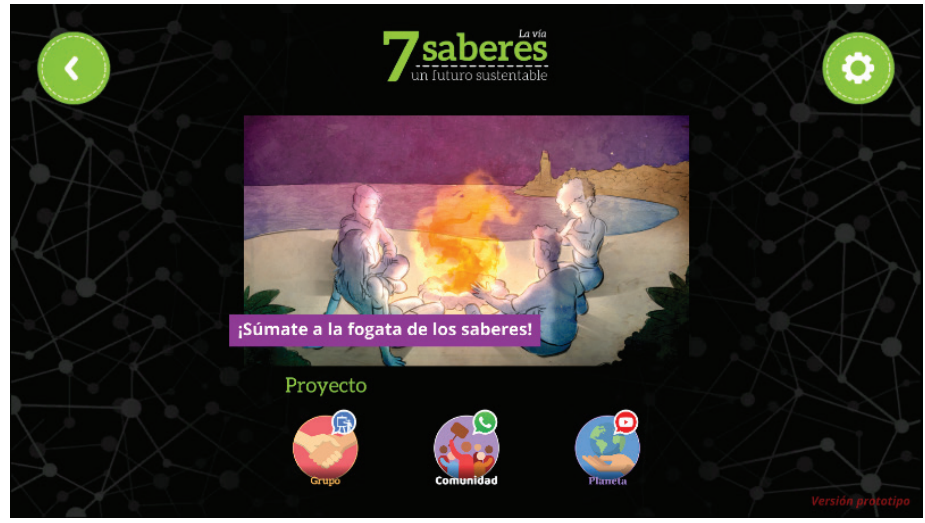

La Aplicación Digital cuenta con botones que permiten abrir distintos espacios de aprendizaje: “Pens@r”, “¿Sabías que...?”, “Resumen", "Actividades". Todos estos botones permitirán abrir un espacio de reflexión personal y colectiva, y trabajo de debate o lúdico. Su sentido es el de ampliar el conocimiento de cada Saber, ingresando por distintas puertas y con caminos diversos. Sus contenidos han sido cuidadosamente seleccionados para mantener a la vez la pertinencia, la coherencia, la calidad y la jugabilidad. Por ejemplo, en el botón "Pens@r" se encontrarán, en cada saber, dos postulados que juegan como provocador de debate y reflexión: un Tweet reciente de Edgar Morin y la cita de un personaje relevante, publicada en el libro "Citations pour la paix / Quotes for Peace" (2015), editado por 
UNESCO y Editorial Gallimard, y que es referenciado en http:// publishing.unesco.org/details.aspx?Code_Livre $=5116$.

Esta Aplicación Digital ha aprovechado una práctica cotidiana del gran pensador francés Edgar Morin, quien a sus 97 años, todos los días envía a través de la red social Twitter uno o varios mensajes breves y con sentido transformador. De los mensajes publicados por Morin en el correr del año 2018, hemos seleccionado uno para cada saber, que permite dar cuenta del sentido del saber en el que se inserta el Tweet.

Por su parte, el "¿Sabías que...?" es un botón que nos lleva a contenidos tales como curiosidades, momentos clave de la historia, o información de gran relevancia, todos ellos elementos que permiten afianzar el saber correspondiente, a través de contenidos atractivos, interesantes y de fácil rememoración.

Una advertencia respecto a las actividades de "Correcto/Incorrecto" y "Múltiple Opción”. El Pensamiento Complejo, es decir, el paradigma epistemológico desarrollado por Edgar Morin tiene, entre sus pilares conceptuales, la noción de "dialógica", que significa la convergencia, simultánea y

Estoy encantado de explorar en la computadora esta Aplicación ya elaborada, a la vez tan viva y tan concreta, que ha sido hecha para invitar a los espíritus jóvenes a entrar en el universo del conocimiento complejo, para aprender las trampas que puede haber de error y de ilusión en todo conocimiento, para entrar en la comprensión, es decir: algo que permite desde ya contribuir con esa reforma indispensable de la educación, para la cual quienes trabajamos en el mundo somos cada vez más.

Esto se concreta de manera extraordinaria en esta Aplicación Digital, que seguramente jugará un rol importante en el futuro en los países de América Latina.

Edgar Morin

París, Setiembre 2018 
complementaria, de contrarios. Es decir, la contradicción es parte de la realidad y la tensión emergente entre contrarios resulta en su motor de existencia y derivas. Por estas razones, no es sencillo operar un ejercicio como el que se plantea clásicamente entre "Verdadero y falso" o "Múltiple opción" en donde sólo una opción es verdadera. Sin embargo, este tipo de ejercicios es sumamente atractivo para el ser humano, y en la Aplicación se quiso integrarlos de manera significativa. Por lo tanto, para mantener la esencia del desafío y a la vez cuidar la coherencia del mensaje del autor (teórico del Pensamiento Complejo), se ha realizado una triangulación en donde algo es correcto o incorrecto no en sí mismo, sino en relación a lo que viene de verse en cada viñeta de la escena o la reflexión de actividades propuestas para cada saber. Esto es válido para los dos ejercicios que admiten sólo una respuesta posible. Asimismo, en el caso de "Múltiple opción", hemos apelado a una fuente inagotable de mensajes con sentido, tales como los que surgen del refranero popular, los proverbios y las frases de personajes célebres.
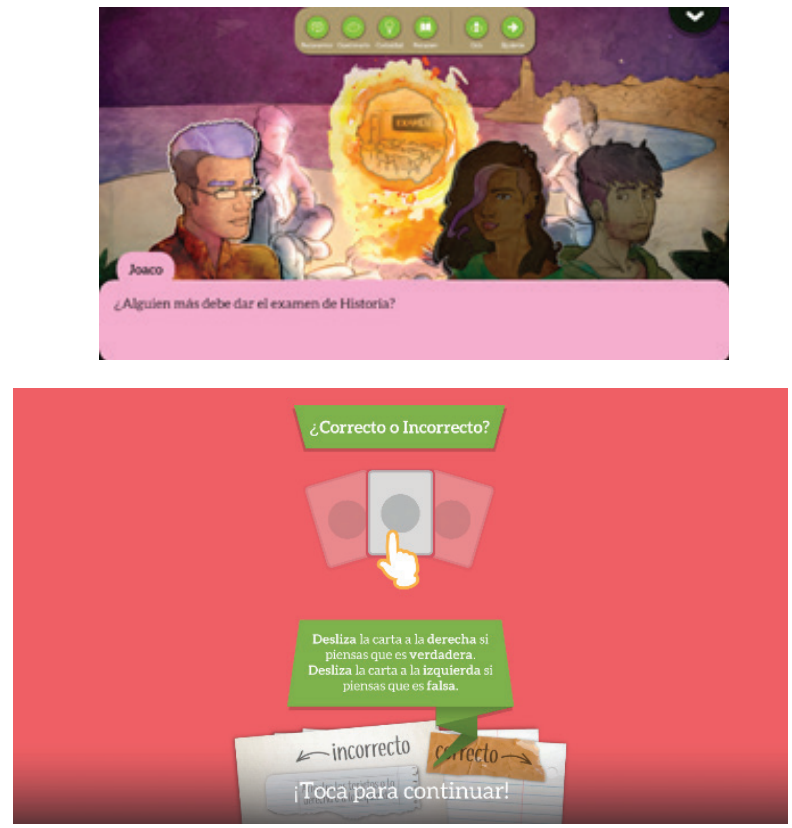
De esta manera, ampliamos el espectro de trasmisión de mensajes yaque, aunquelos postulados que se presentan no sean loscorrectos en ese caso, sí de cualquier forma proponen buenos sentidos de las cosas y funcionan como un elemento colateral positivo.

Las Actividades que se sugieren al docente para realizar en aula o en domicilio son sencillamente orientaciones que se proponen desde la Aplicación Digital como insumo para el proceso de aprendizaje. Sin embargo, es importante enfatizar la importancia de la libertad del docente para crear las propias actividades que entienda oportuno, y así aprovechar mejor los contenidos de esta herramienta. Por supuesto, es muy importante enfatizar la necesaria coherencia del mensaje que la actividad pueda enviar al estudiante. Por ello, es de gran relevancia la lectura comprensiva y previa, por parte del docente, del texto del autor en su versión original.

\section{Unidad de Proyectos}

Una vez que se ha transitado por los distintos saberes, con una comprensión avanzada del sentido y necesidad de esta mirada para comprender mejor el mundo y sus desafíos cotidianos, es hora de poner en práctica lo que el estudiante (y el docente) han trabajado en este camino. La Unidad de Proyectos ofrece la posibilidad de concretar vivamente la capacidad de mirar críticamente la realidad, identificar sus oportunidades de mejora, y proponer alternativas estratégicas para ello, todo esto con referencia a alguno o varios de los saberes abordados en la Unidad Central de la Aplicación.

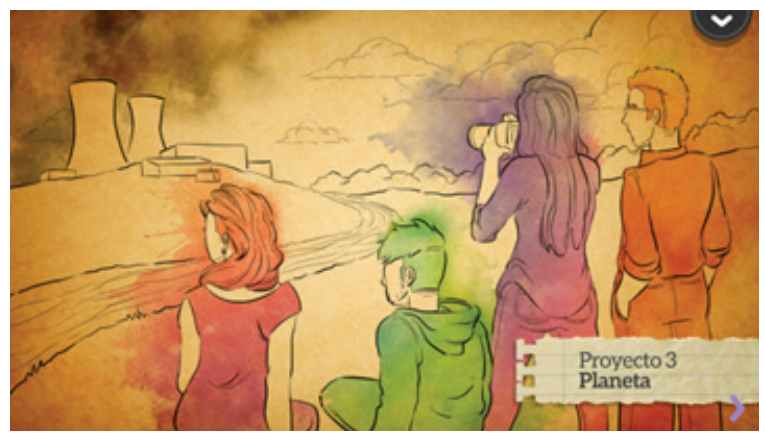


Para ello, se propone un trabajo en tres niveles: el grupo, la comunidad y el planeta. En cada caso la escala y las problemáticas podrán ser distintas, pero la mirada es coherente con los saberes aprendidos. El ejercicio que se propone a los distintos grupos de estudiantes involucrados es claro: 1) observar un escenario específico (grupo de aula, comunidad, planeta); 2) identificar un problema o una oportunidad de mejora; 3) proponer una estrategia de solución; 4) fundamentar el proceso de análisis y propuesta en base a alguno o algunos de los saberes; 5) en base a todo lo anterior, elaborar un producto a ser compartido (exposición en nivel aula, poster en nivel comunidad, video en nivel planeta). Estos distintos productos serán compartidos con las escalas correspondientes, a saber: la exposición será presentada en su grupo de aula o en la comunidad académica del centro educativo; el poster será difundido a través de redes como WhatsApp o Instagram; el video será subido a YouTube. De esta manera, alcanzarán las audiencias a nivel de pequeño grupo, comunidad o escala global.

Por supuesto, la potencialidad del uso de los productos elaborados en este proceso es alta. La creatividad potencial y las oportunidades para su divulgación e impacto pueden ser aprovechadas por los estudiantes, los docentes o la institución de formación. De esta forma, se estarán elaborando diagnósticos y propuestas desde el paradigma de la complejidad y la obra de los "siete saberes". Se trata de una invalorable cantera de posibles transformaciones concretas de la realidad que nos circunda.

\section{Del rol docente en la Aplicación}

Es muy importante señalar la particularidad del rol docente en el uso de esta Aplicación Digital Educativa. En realidad, estamos frente a la conjunción de tecnologías digitales con metodologías educativas y contenidos particulares. Es un desafío en sí mismo, tanto para los diseñadores, como para los docentes y la institución en la que se instale. 
Por estas razones, es de la mayor relevancia señalar que el rol docente aquí impone una función de tutor/acompañante, pero no magisterio clásico. Aquí no hay UNA verdad, ni quien la detente. Aquí hay una oportunidad de reflexión conjunta, en donde lo que se va a fortalecer es el paradigma interpretativo de la realidad, y (ojalá) también la realidad a través del aprendizaje y las propuestas.

Por lo mismo, el docente está llamado también a incluirse en el proceso de aprendizaje, disponiéndose a transformar su propia forma de concebir los asuntos, de pensar la educación y la vida, de imaginar su rol como persona, de profundizar el propio conocimiento sobre la condición humana.

Como bien recuerda Edgar Morin, es urgente avanzar hacia una reforma indispensable de la educación, y creemos firmemente que iniciativas de este tipo aportan en este sentido.

\section{Referências}

Carta de Fortaleza. Disponível em: http://www.ecologiaintegral.org.br/Carta \%20 de $\% 20$ Fortaleza.pdf

Conferência Internacional. Disponível em: http://uece.br/eventos/spcp/anais/ carta_de_fortaleza_ii.html

MORIN, E. Os sete saberes necessários à educação do futuro. Disponível em: http://unesdoc.unesco.org/images/0011/001177/117740so.pdf

Proyecto La vía de los 7 saberes: http://www.7saberes.org/

70 Citacions pour la paix. Paris: UNESCO; Editorial Gallimard. Disponível em: http://publishing.unesco.org/details.aspx?Code_Livre= 5116 